\title{
Educação Inclusiva numa Visão Crítica do Currículo: Currículo, Cultura e Inclusão um Modelo que Pode Transformar a Educação do Público Escolar
}

\author{
TRIGUEIRO, Edla Maria Gonçalves de Alencar ${ }^{[1]}$
}

TRIGUEIRO, Edla Maria Gonçalves de Alencar. Educação Inclusiva numa Visão Crítica do Currículo: Currículo, Cultura e Inclusão um Modelo que Pode Transformar a Educação do Público Escolar. Revista Científica Multidisciplinar Núcleo do Conhecimento. Ano 03, Ed. 06, Vol. 01, pp. 13-29, Junho de 2018. ISSN:2448-0959

\section{Resumo}

Este trabalho vem apresentar possibilidades encontradas numa pesquisa bibliográfica com o objetivo de agregar valores e importâncias concretas da educação inclusiva com a educação para todos, fazendo-se uma reforma complexa na maneira de trabalhar a educação. Através dessas possibilidades, ações de integrações e interações inovadoras desenvolver junto aos julgados não serem capazes de obter o conhecimento por sua diferença visível e invisível aos olhos de uma sociedade que costuma ditar regars e querer estar sempre a frente de tudo e de todos, para decidir o que é importante para eles a sua maneira. Ter-se-a de dizer que através dessa pesquisa chegou-se a aspectos da história do currículo e pôde ser feito uma melhor compreensão do significado e sua importam cia relacionando a cultura. Não fixando-se ao passado, buscou-se atentar ao presente da educação e criar possibilidades para o futuro, envolvendo comunidade escola, pais, e a sociedade. Recomenda-se pensar em um modelo de escola na atualidade onde inclusão se faz presente mas não acontece como se deseja para com esse público alvo. É desta forma que pensamos na união de um currículo, cultura e inclusão para uma educação inclusiva numa visão crítica do currículo, para transformar a educação na formação de cidadãos, não apenas formar possíveis trabalhadores. Entende-se que através dessa união formação em todas as camadas da sociedade.

Palavra chave: Currículo, Cultura, Educação, Possibilidades, Inclusão.

\section{Introdução}

O presente artigo tem como principal finalidade analisar e expor as pesquisas realizadas através de referências bibliográficas para dar suporte ao desenvolvimento educacional para todos através um 
currículo crítico. O pensamento complexo relacionado à educação de modo geral deve conter a parte referente ao todo no sentido geral. Essa será a ação da educação inclusiva, relacionadas aos avanços que o currículo adequado e flexível juntamente com a valorização da cultura vinda com os alunos possa favorecer o desenvolvimento desse público alvo.

A educação estava separada em suas regras de alcance para defender em conjunto uma formação de saberes com qualidade aos cidadãos proporcionando uma vida melhor no mundo seletivo de aparência e qualificações. Essa complexidade das educações moldadas com um currículo relacionada as idéias de uma sociedade, unir culturas fortalecerá a identidade de cada pessoa, analisando e aprendendo com cada individuo envolvido. $\mathrm{O}$ aprendizado deverá ser para todos e no sentido real do coletivo esquecendo o individualismo.

Os estudos nos últimos séculos no Brasil faz do currículo um objetivo de pesquisas em diversas linhas de investigação. A realização entre trabalhos pedagógicos e as práticas curriculares ajuda a compreender que o currículo precisa de um contexto onde o sujeito e outros interessados em construir um saber devem receber orientação através de um currículo direcionado as suas reais necessidades. Os menos favorecidos diante de uma globalização são vítimas das ações econômicas e sociais.

Relacionar conhecimento sobre a união do currículo, cultura e inclusão é a concretização para que a educação aconteça atingindo a todos. Nesse contexto alunos e professores tem papel específicos no desenvolvimento deste currículo escolar. No caso dos professores seu papel é de elaborar de forma direta seus projetos partindo das orientações do currículo, com suas experiências e legitimidade de saberes e autoridade em solucionar os possíveis problemas que venham surgir buscando ser flexível em modificar algumas ações que esteja na formação do seu projeto inicial e adaptar em comum acordo as necessidades do público envolvido que for ser assistido durante sua responsabilidade.

As questões das práticas curriculares analisadas em todos os estágios da educação, desde as séries iniciais ao ensino superior, mostra em termos o quanto é preciso ser ampliado com maior claridade o currículo incluindo a percepção da cultura do individuo e o quadro da deficiência que o coloca na lista dos incluídos diante dos preconceito sociais. Os gestores que estão a frente na elaboração do currículo precisam ter um olhar de conhecimento sensível que possa analisar diferenças, semelhanças e necessidades para com o público dos diferentes sociais, mas que são assistidos legalmente na LDBEN de n ${ }^{\circ}$ 9.394/96 que garante educação para todos.

Como se dará a educação inclusiva numa visão crítica do currículo, essa é a maior preocupação desse trabalho. Essa pesquisa ainda não tem referências suficientes para por a prova a suficiência se as ações que vier a ser implantadas vão resolver por completo o que realmente é preciso para uma educação, essas questões perpassam a escola, é preciso que alcance todos sem descriminação. Cabe ainda outras analises de currículos, culturas e de inclusão através de outras pesquisas.

\section{Quem é o público inclusivo}

Diante desse dilema de uma confusa versão para falar sobre quem realmente faz parte dos diferentes, as escolas que atendem de forma de educação inclusiva em algumas regiões apenas têm a preocupação em acolher os deficientes e esquecem o público que está em margem de risco, os que sofrem abuso de qualquer condição social, os artistas circenses, os destinados por ter aparência visível que foge aos 
padrões da normalidade e outros envolvidos.

Tomando por exemplo a deficiência auditiva e de sua característica a surdez é "uma deficiência não visível fisicamente que se limita a atingir uma pequena parte da autonomia do individuo" ou, ainda, como a ausência, dificuldade ou inabilidade para ouvir, sons específicos, de ambientes e os sons da fala humana (FERNANDES, 1989, P.38) Sobre essas definições alguns autores acreditam que somente informações clínica podem afirmar o grau da surdez, e para que o trabalho educacional no sujeito surdo seja de qualidade o educador deve buscar conhecer sobre a cultura e diferença lingüística da comunidade surda (STROBEL \& DIAS, 1995, p.7-8).

Há escassez de historia cultural de surdos, pela falta de registros que muitas gerações não faziam suas narrativas na modalidade escrita, pouquíssimos registros, porém riquíssimos tornaram público a existência da língua de sinais já utilizada entre ouvintes e surdos, é muito importante se aprofundar na cultura surda como diz Walter Benjamin (1892-1940): “é fundamental preservar a memória daqueles que não tem lugar nos manuais de historia, salvaguardar os testemunhos e depoimentos".

Estudos mostram que existem diferentes categorias de identidades surdas comprovando assim uma heterogeneidade na construção de grupos ou de comunidades surdas. Segundo SKILLAR, 1998 as identidades surdas tem a seguinte forma: uma identidade surda política que predomina a experiência visual com o uso da língua de sinais; uma identidade surda híbrida que os surdos usam às vezes a língua de sinais e outras vezes oral dependendo do momento; uma identidade surda de transição que é caracterizada pelo momento que o surdo esta passando do mundo dos ouvintes para o convívio com outros surdos; uma identidade surda incompleta é a que o sujeito surdo vive sobre pressão de todas as outras identidades para não se identificar com outros surdos; e uma identidade surda flutuante na qual esses surdos não se aceitam como surdos e buscam levar uma vida como os ouvintes.

"Como se sabe, a língua além de ser o principal veículo de comunicação, é também o mais importante meio de identificação do indivíduo com sua cultura e o suporte do conhecimento da realidade que nos circunda. O problema das minorias linguiísticas é, pois, muitas vezes, não apenas a privação da língua materna, mas, sobretudo a privação de sua identidade cultura"

\section{Lucinda Brito}

A importância de cada pessoa ter sua cultura e através desse conhecimento o seu desenvolvimento possa ser valorizando e agregado aos outros saberes culturais que passaram a estar juntos na formação do saber dentro das escolas de ensino regular, onde se percebe que "tornou-se lugar comum destacar a diversidade das formas culturais do mundo contemporâneo" (Silva, 2005, p. 85.) As minorias devem ser aceitas e o currículo crítico ser racionalizado para não errar no atendimento para esses futuros cidadãos.

Crenças, mitos, lendas e contos populares interpretavam de forma negativa os diferentes e suas condições culturais, e suas limitações aparentes acabavam por deixá-los em situação de exclusão. Dessa forma "a política curricular, metamorfoseada em currículo, efetuava, enfim, um processo de inclusão de certos saberes e de certos indivíduos, excluindo outros" (Silva, 2001, p. 11). Fica assim a informação que existe uma negligência para com o comportamento, as atitudes e os conhecimentos dos diferentes que envolvem todos os deficientes e marginalizados sociais por qualquer problema que os colocou nessa lista. 


\subsection{A inclusão pela existência da exclusão}

Estudos se voltaram para mostrar a historia da luta de diversos sujeitos para descentralizar o poder em que nas políticas públicas a minoria surda e outras áreas das deficiências acabavam sendo prejudicados todos por causa da exclusão de uma política movida por interesses, onde era mais viável fabricar sujeitos anormais, onde a surdez era considerada doença e em muitos casos demência do sujeito que era julgado incapaz de aprender, de ser alfabetizado, ficando assim marginalizado e excluído, esse ato ou ação de incluir só se dava pelo fato de que antes a exclusão favorecia um maior rendimento a políticas públicas. Como fala Ronice: "Permita-se "ouvir" estas mãos, somente assim serão possíveis mostrar aos surdos como eles podem "ouvir" o silêncio da palavra escrita. "(Ronice Miller de Quadros)

"Nós, os surdos, precisamos ser incluídos no contexto social. Incluir não é dar oportunidades para mostrarmos nossa capacidade, pois não precisamos provar nada para ninguém, a boa intenção não é inclusão. "Inclusão é incluir pelos talentos e não pelas limitações."

Solange Quatrin- instrutora surda-Foz do Iguaçu - 2003

Durante anos foram produzidos os excluídos, e aqueles marginalizados do meio social e, coletivo. Nessa forma de pensar o que fez existir a inclusão foi o simples pôr complexo fato de a exclusão ter força de caráter econômico aos organizadores dessas políticas públicas vigente. Essa força veio perdendo seu objetivo quando a sociedade se fez mais humana ao que estava sendo jogado debaixo dos tapetes da sociedade. O Decreto ${ }^{\circ}$ 5.626/05 que promoveu a Língua Brasileira de Sinais-LIBRAS como a segunda língua oficial do povo surdo no Brasil e com o poder para modificar o currículo escolar para atender o sujeito surdo, tornando esse currículo no quesito especifico para as novas políticas inclusivas nas faculdades e universidades com adequação vigente a legislação que reconhece e oficializa a língua brasileira de sinais a Lei $n^{\circ} 10.436 / 2002$ e seu Decreto $n^{\circ}$ 5.626/2005 uma disciplina obrigatória para os cursos de Magistério e de licenciatura em geral e no curso de Fonoaudióloga.

"Quando eu aceito a língua de outra pessoa, eu aceito a pessoa. Quando eu rejeito a língua, eu rejeitei a pessoa porque a língua é parte de nós mesmos. Quando eu aceito a língua de sinais, eu aceito o surdo, e é importante ter sempre em mente que o surdo tem o direito de ser surdo. Nós não devemos mudá-los, devemos ensiná-los, ajudá-los, mas temos que permitir-lhes ser"

\section{Terje Basilier}

Todo esse trabalho é para buscar entender o porquê a LIBRAS, sendo ela a língua materna do povo surdo, que tem as mesmas necessidades de atendimento educacional, saúde, lazer, esporte, gastronômico, mercado de trabalhos amplos dentro outros, recebe tão pouco atenção por parte dos responsáveis pela formação de novos profissionais que estarão de forma direta à frente desses publico alvo os surdos. A Libras como L2 nas Instituições de Ensino Superior de Araguaína vem apenas no cumprimento da Lei $\mathrm{n}^{\circ}$ 10.436/2002 e de seu Decreto n 5.626/2005 ficando optativa nos cursos da área de saúde e outras áreas de mesma importância para os dois tipos de publico de interesse e que receberam atendimentos pelos profissionais que estão em formação.

A que ponto a falta do conhecimento da Libras, atrapalhará, sendo uma disciplina de opção nos cursos de formação superior da área da saúde como odontologia, enfermagem, farmácia, educação física, medicina 
e outros que direta ou indiretamente estarão recebendo o público surdo. Os demais cursos que em caráter obrigatório recebem a Libras nas instituições de ensino superior de Araguaína como a pedagogia está recebendo conteúdos voltados à área especificam do curso ou apenas a Libras para iniciantes. Esse cuidado sobre o conteúdo ser voltado para as verdadeiras necessidades do curso facilitará a compreensão e a importância dos atendimentos com o publico alvo. Esse currículo não foi preparado para atender a minoria que dependerá dos futuros profissionais que saíram dessas instituições.

\section{O currículo crítico e as mudanças na educação}

Garantir acessibilidade de locomoção e comunicação em suas dependências, desenvolver metodologias e práticas pedagógicas que venham atender as demandas individuais ou em determinado grupo será de obrigação para todas as instituições de ensino, na alfabetização até mesmo no ensino superior, mas certamente as dificuldades em se fazer um currículo adequado a cada realidade local será ainda um grade problema para a educação inclusiva que também valoriza a cultura. A proposta inicial é de um currículo flexível, mas que na realidade não venha a ser aplicado e muito menos redirecionado ao que for surgindo durante o processo de ensino e aprendizagem. Essa mudança de olhar o currículo crítico deve ser decisiva para cobrir as necessidades educacionais da área da inclusão que estão relacionadas com o processo de ensino aprendizagem de modo geral.

O currículo deve considerar uma legislação brasileira educacional já ultrapassada, devido à preocupação inicial não incluindo os diferentes e deficientes, que estavam fora dos padrões de interesse das indústrias de produção em larga escala. As leis de diretrizes políticas necessariamente não atendiam as exigências para a época, é entendido que educação inclusiva não se aplica de maneira fácil, inclusive aos que são deficientes. A qualidade de ensino deve ser a maior preocupação para que possa acontecer o aprendizado. As instituições de ensino devem oferecer um ensino de qualidade para todos os estudantes e reorganizar suas estruturas de funcionamento e metodologias para que o currículo seja adaptado e garanta que os profissionais que atuam na educação tenham consciência de sua importância na prática do ensino e as escolas se tornem verdadeiramente inclusivas.

\section{Regras para uma educação inclusiva na visão do currículo crítico}

Todos os alunos que formam o público alvo inclusivo precisam receber durante sua formação educacional inicial, ação que devam estar presentes na cultura, valorizando cada pessoa em sua individualidade de conhecimento aproveitando cada beneficia que o currículo crítico possa fazer positivamente para que todos possam obter conhecimento.

"Para a Pedagogia, Histórica-Crítica, a educação é o ato de produzir, direta e intencionalmente, em cada indivíduo singular, a humanidade que é produzida histórica e coletivamente pelo conjunto dos homens".

\section{SAVIANI, 2001, p.30}

Segundo ainda o autor Saviani, a sociedade de forma consciente determina as prioridades de forma crítica para estar atendendo a minoria em todos os efeitos dentro da educação que sempre sofreu com essas interferências, prejudicando assim a toda educação e desenvolvimento educacional de ouvintes e os surdos diferentes e semelhantes temos como exemplo o Congresso de Milão em 1880, que proibiu por um 
século inteiro o uso da língua de sinais em todo mundo, acontecido esse que marcou com perdas irreparáveis a historia dos surdos em todo mundo no âmbito de sua identidade e cultura surda.

A educação é um trabalho para ser realizado em união, não existe saber para apenas uma pessoa, a educação não acontece nas escolas de dentro para fora, ela precisa do saber de fora para dentro, aonde a cultura de cada pessoa venha para unir, e atender os diferentes. A inclusão escolar é diferente de educação inclusiva e não pode acontecer de forma desordenada, precisa de direcionamento e posicionamento.

\subsection{O apoio legal para uma educação inclusiva}

Os documentos que organizam a educação regular são válidos para atender todo público e que os direitos sejam garantidos pela Lei de Diretrizes e Bases da Educação Nacional (LDBEN) nº 9.394/96 que mudou os ângulos da educação e da educação inclusiva para garantir as melhorias e suprir as necessidades desses alunos. O currículo era garantido através dos Parâmetros Curriculares Nacionais (PCN's) que o Ministério da Educação (MEC) criou para orientar os professores sobre os conteúdos que precisariam ser apresentados nas escolas durante o ano letivo através de atividades individuais e em grupo. Não existe e nem vai existir currículo especial para nenhum tipo de público, existe um currículo moldado para atender a todos na educação, porém as aplicações sim devam ser diferentes.

"desde o primeiro dia, todos os alunos devem estar envolvidos em atividades interessantes, que valham a pena ser aprendidas e que os envolvam ao Maximo com seus colegas de aula. Não fazer nada ou realizar atividades isoladas, tendenciosas ou frustrantes pode levar qualquer aluno a não gostar do ambiente [...]

Stainback, p. 235, 2008.

A participação e envolvimento de todos é "ação de inclusão" as atividades desenvolvidas dentro e fora da sala de aula e responsável por formar integração e interação, senso de trabalho em grupo, socialização e os alunos aprendem o máximo que podem em atividades diárias compostas por disciplinas e recursos envolventes onde o aluno se sinta bem e seguro com o que é ofertado. Todos os alunos quando recebem a oportunidade para aprender com igualdade os objetivos são alcançados mais rápido.

Afirma-se que é através do currículo que as coisas acontecem nas escolas, que sua composição curricular garante de forma sistematizada os esforços pedagógicos, mas na verdade a elaboração deste currículo crítico a realidade que possa garantir uma perspectiva multicultural. É necessário viver a inclusão educacional como proposta da sociedade e da escola, os professores não precisam ser especialistas, mas assumir o ensinar, o que ensinar e como ensinar para o aluno com deficiência, rompendo com os modelos de currículos únicos, romper com os modelos de escolas tradicionais e inflexíveis diante das problemáticas que surgem no âmbito escolar. Benjamin (1892-1940) disse: "é fundamental preservar a memória daqueles que não tem lugar nos manuais de história, salvaguardar os testemunhos e depoimentos." Escrever uma nova história não para apagar o pouco e sujo que existiu sobre a não prática inclusiva, mas uma versão que valorize os conhecimentos e suas capacidades independentes de que recebera essa saber.

A educação Inclusiva é regulada por várias normas fundamentadas na Constituição Federal de 1988 que determinou igualdade de condições para o acesso e a permanência nas instituições de ensino para todos com atendimento especializado para todos preferencialmente no ensino regular. É fortemente evidenciado 
nas Leis destacando o Decreto Federal N³956/2001 que promulga a Convenção Interamericana que venha eliminar de todas as formas de discriminação contra pessoas com deficiência (Convenção da Guatemala) e o Decreto Federal No 6949/1996, que promulgou a Convenção Internacional sobre os direitos das Pessoas com Deficiência- CDPD/ONU/2006.

Consta na Lei Federal de Diretrizes e Bases da Educação No 9.394/1996 e na Resolução CNE/ CEB Nº 02/2002, que institui Diretrizes Nacionais para Educação Especial na Educação Básica, a questão de um currículo diferenciado e flexível para os alunos que formam esse público alvo da Educação Inclusiva, em que consta no documento Política Nacional de Educação Especial na Perspectiva da Educação Inclusiva (BRASIL, 2008) grandes mudanças para buscar uma organização ao sistema educacional, como uma transversalidade da educação desde o ensino infantil até a educação superior, um atendimento especializado com continuidade de escolarização, formação de professores para esse atendimento especializado, uma participação com maior intensidade das famílias e também das comunidades, uma acessibilidade implantada nas escolas para tornar o acesso mais pratico para todos com sua composição mobiliária, transportes com participação intersetorial na implementação das políticas públicas.

Deve ser ofertada também nas escolas Atendimento Educacional Especializado (AEE), educação ara surdos com o amparo de um interprete em sala de aula e reforço intermediário em sua língua materna a LIBRAS (Língua Brasileira de Sinais) oficializada pela Lei de Libras No 10.436/2002, regulamentada na Lei Federal No 10.098/2000(Lei de acessibilidade).

Ainda não temos uma solução para o assunto proposto aqui, mas inclusão precisa urgentemente ser implantadas na educação juntamente com a valorização da cultura e da inclusão real. Os diferentes e os surdos só precisam de um olhar mais humano para que os profissionais ou os responsáveis pelos currículos das escolas do ensino regular possam estar refazendo seus currículos através de uma ação incisiva para que assim todos possam ser usuários plenos dos serviços de educação e saúde em todos os níveis e em outras áreas esquecidas pela sociedade em deveria estar incluído todos.

\section{Um currículo não adaptado aos excluídos na visão cultural}

Falar inicialmente sobre cultura é preciso fundamentar a questão de identidade, e das possíveis crises de identidade que podem acometer uma pessoa ou uma comunidade. Em nossa sociedade os saberes nem sempre são repassados por medo ou por questões pessoais e em grupo. Questões sociais interferem no repasse do conhecimento, incluindo o preconceito, falta de ética, falta até mesmo da importância da divisão do saber. Através desse repasse de informação é que se constrói a cultura de uma comunidade ou de uma sociedade. Esses saberes formados ou não por idéias comuns devem ser divididas e interagidas para que se consolide a identidade cultural.

Este trabalho vem mostrar a realidade da importância da identidade cultural do ser humano, especialmente os que durante muito tempo estiveram atrás de uma sociedade cheia de desprezo e de orgulho para assumir os excluídos. Esse público alvo durante séculos não pode formar nem assumir sua própria identidade cultural, simplesmente eles muitas vezes eram proibidos de circular entre os considerados normais e de identidade cultural já definido e assim considerados superiores. Uma parte da comunidade sociológica encontra-se dividida em uma questão de em como aceitar os deferentes. A aceitação por parte da maioria simplesmente tornaria a vida desta minoria bem mais prática e a identidade cultural de cada um deles poderia ser formada com maior qualidade para se por em prova na sociedade 
Em meio à modernidade, as culturas que se divergem, vêm em reforço para gerar no individuo sua identidade cultural. A formação de cultura se faz dos pedaços de informações vividas, de informações sabidas, da ingenuidade ou de ser sagaz diante das ações ocorridas em sua vivência, que repassada em forma de saberes contribui para que outros adquiram novos saberes. A cultura não pode ser retirada do ser humano, apenas acrescentada de acordo com a necessidade que esses seres estejam precisando. Não pode ser dividida, apenas somada, mas essa soma não torna essa cultura única para todos, pelo contrário essa cultura será única para cada pessoa devido ao que esse ser humano absorve mediante sua necessidade e pretensão de como quer viver. Para Edward Tylor definir cultura é como:

"complexo que inclui conhecimentos, crenças, arte, moral, leis, costumes e quaisquer outros hábitos adquiridos pelo homem como membro da sociedade"

\section{LARAIA, p. 25, 2008.}

Os lugares, cidades, capitais e países nunca vão sair de lugares, permaneceram fixos, mas as pessoas que vivem ou estão de passagem por estes lugares, estes sim sofrem mudanças importantes para sua formação cultural que a cada dia adquirem mais informações, seus códigos de referências e características importantes para as transformações do ser humano. Cultura pode ser entendida como idéias colocadas em práticas e partilhadas para beneficiar o maior número de pessoas e nunca de uma única pessoa. O saber do outro entra como reforço para ampliar e não para por medo aos outros em seus pensamentos por estar certo ou errado. Tantos os lugares como a sociedade começam a sofrer uma transformação positiva e fundamental para que venha ser colocada em prática para beneficiar todos.

Antes, apenas as pessoas consideradas normais poderiam participar desta troca de informações e absorver as novas idéias receber nem heranças, nem saberes. As pessoas com alguma deficiência aparente ou invisível, no caso dos surdos, esses viviam explorados, onde não podiam receber nem heranças, nem casarse para não gerar mais anormais. Alguns registros através da história trazem informação dos maus tratos, isolamentos e espaçamentos para que estes não sinalizarem com as mãos assim como os cegos e deficientes físicos, para não chamar atenção de sua deficiência perante a sociedade.

A humanidade durante o decorrer da história registros sobre tudo o que foi produzido de maneira positivo por ele, dentro das questões de saberes literários, filosóficos, científicos, artísticos e outros, assim a cultura era durante todo esse período como uma cultura única e universal. Muitos estudos no campo interdisciplinar vieram para democratizar a cultura. Segundo Brandão (2009) os saberes não pedem permissão a academia ou a qualquer outras instancias oficiais para expandirem-se socialmente. Para Duschatzky \& Skliar (2000) a fabricação de uma imagem do outro funcionava para "classificar as pessoas que não são como nós" e "enquadrá-las em aparatos pedagógicos, assistenciais ou terapêuticos que os enquadram em nossa razão de ser, na nossa cultura e identidade.".

Para estar verdadeiramente colocada em práticas essa educação inclusiva se faz necessários estudos, analises e discussões locais a realidade de Araguaína para que as problemáticas sobre o que realmente incomoda esse público desassistido venham encontrar solução nas ações inclusivas sugeridas anteriormente. Como diz Dermeval Saviani "[...] chegam à conclusão de que a função própria da educação consiste na reprodução da sociedade que ela se insere" Não temos como negar que existe uma exigência enorme para se fazer programar essa educação inclusiva dentro das escolas em geral, mas não bastara somente a boa vontade de uma minoria em fazer acontecer. 
"Todos e cada um de nós nos descobrimos existindo no mundo (existência que é agir, sentir e pensar). Tal existência transcorre naturalmente, espontaneamente, até que algo interrompe o seu curso, interfere no processo alterando a sua seqüência natural. Aí, então, o homem é levado, é obrigado mesmo, a se deter e examinar, procurar descobrir o que é esse algo. E é a partir desse momento que ele começa a filosofar. $O$ ponto de partida da filosofia é, pois esse algo a que damos o nome de problema " SAVIANI, p. 17, 1985.

Essa inclusão exige rupturas, investimentos e formulações necessárias para que tudo funcione. Durante essa pesquisa de referência bibliográfica para entender o que acontece com os diferentes nas escolas regulares tomando também o caso do numero de surdos em Araguaína que já ultrapassa 1152 deficientes auditivos entre crianças, adultos e idosos com quadro de leve, modera, severa e profunda perca de audição com maioria de CID n ${ }^{\circ}$ H 91.3 e H 90.3, variando entre bilateral, unilateral, reversível e irreversível. Ficou claro o tamanho do descaso na educação, em que a maioria ainda está afastada das escolas.

Para que a educação a esse público tenha uma maior qualidade à escola de atendimento inclusivo pode ser definida como aquela que educa todos os alunos em salas de aula regulares e proporciona a eles oportunidades educacionais adequadas e desafiadoras, porém ajustadas às necessidades e habilidades de cada um. Desta forma, os alunos com deficiência ou sem deficiência tenham a oportunidade de se preparar para a vida na comunidade, aprendendo a viver e conviver com a diferença colaboradora e atuante na sociedade. Os professores, por sua vez, ampliam sua visão do que é ensinar e aprender desenvolve a criatividade e crescem como pessoas e como profissionais, esse perfil levará os alunos aos estudos de nível médio e superior com menos dificuldades.

\section{A cultura e seu poder dentro da escola apoiando a inclusão social}

Para uma mudança na educação o currículo, cultura e inclusão devem ser revistos em sequiência com objetivos únicos em atingir de acordo com as necessidades de cada aluno. Essa união de ação educacional favorecerá a uma adaptação múltipla e o professor entrará como ator principal nessa jornada. As possibilidades desta união trarão o sucesso da escola e automaticamente dos alunos. Não se pode negar a escola como instituição cultural, com sua formação em dados históricos, essa cultura que chega para as escolas vem recheada de situações e valores que relacionados à idéia de garantir o direito à educação para todos e direito a escola.

Nas questões de linguagem como parte de sua cultura, o aprendizado da primeira língua é importante, ninguém "escolhe" a sua pátria, mas tenha que de fato aprende-la envolvendo todos os aspectos definitivos. As ordens das idéias no aprendizado da língua são de fator cultural. Tomando novamente como exemplo do surdo, quanto mais ele conviver com outros surdos, a possibilidade de construir sua identidade cultural será confirmada com qualidade. A cultura do surdo vai ser o que ele é e sua vivência em meio à comunidade de surdos e de ouvintes. A cultura dos demais não é diferente, pois eles vão trazer o que vivenciam entre suas famílias e suas limitações em suas deficiências.

Dentro das várias sociedades existem as divergências culturais. Não é diferente dentro das comunidades de surdos que se dividem em uma mesma cidade ou em mesmo estado. Eles se tornam estrangeiros dentro de um mesmo país ao usarem sua língua materna a Língua Brasileira de Sinais (LIBRAS), que é repassada com forte influência cultural de cada comunidade. A cultura não é uma formação única e muito menos estática, passa por adaptações, a cada dia ou de acordo com a necessidade que o individuo ou os 
integrantes de determinadas sociedades se sintam em necessidade imediata para tal mudança. É esse contato com diversas culturas que faz do ser humano capacitar-se a mudanças para o bem viver em meio à sociedade globalizada. Esse processo de socialização com a cultura do outro é que caracteriza a flexibilidade para adquirir o saber.

Não apenas as escolas e as famílias envolvidas desse público citado são os responsáveis por uma interação e integração deles ao meio social. As questões que envolvem os direitos a uma educação com qualidade seguem as definições do MEC e da LDBEN. Essa Lei específica aquelas pessoas que não alcançaram um nível intelectual e ou comportamental de absorver o saber e os superdotados para estarem integrados as escolas em salas comuns do ensino regular. A cultura desse público é tão rica quantas outras culturas de fundamental importância para que através de suas experiências se possam construir um saber determinante para sua vida futura.

Os professores podem e devem buscar uma efetivação do aprendizado dos alunos. O docente não pode simplesmente transmitir as experiências culturais em evidência, devem contextualizar os saberes e articulá-los ao conhecimento junto com a vida no processo do tempo desses discentes envolvidos em cada momento histórico de cada um dos envolvidos.

\section{Considerações finais}

A partir do que foi exposto, fica claro ver que as questões da educação inclusiva numa visão do currículo crítico, contando com a união do currículo, cultura e inclusão, podem ser avaliados como transformadores da aprendizagem?

Essa avaliação pode ser vista como instrumento que auxiliará com objetivos que devam ser únicos para alcançar o saber. Todos os envolvidos reagiram de maneiras diferentes na construção do saber, porque o que é importante para um não seja necessário para que todos e assim nem todos aproveitem os mesmos conteúdos e ações envolvidas. A educação ainda não tem profissionais para atender as reais necessidades desse público alvo e muito menos da área da especial em modo geral.

Professor sem tempo para capacitações, devido ao excesso de trabalho para garantir suas sobrevivências com a família, falta de espaço físico, falta de acolhimento para com a minoria dos diferentes que querem estudar e não conseguem por falta do comprometimento das escolas e instituições de ensino são preocupantes, para refazer seus currículos incluindo novos recursos como disciplina para estar de maneira inclusiva realizando os direitos dos diferentes em ser atendidos em meio a sociedade majoritária.

Isso é resultado de uma exclusão da política pública regente para a educação que não tem consciência crítica. A educação e política são faces opostas de uma moeda corrente dentro de um país gigantescos com vários brasis em um mesmo Brasil onde a educação é uma prática idealistas e a política uma realista que podem coexistir de maneira pacífica e respeitar mais as diferenças e dar oportunidades a todos.

Essa vontade de educação se encontra em muitos professores porem em número insuficiente para tornar realidade. A educação inclusiva na visão do currículo crítico precisa ser elaborada, necessariamente por pensadores educacionais críticos e transformadores criadores de possibilidades diante das impossibilidades impostas pelas normas sem rumo, tornando assim um trabalho de grupo de educadores éticos e de moral por uma educação inclusiva para uma maioria da população e nunca mais pensando em 
uma minoria.

\section{Referências bibliográficas}

BRASIL. Ministério da Educação e do Desporto. Parâmetros Curriculares Nacionais: pluralidade cultural/orientação sexual. Secretaria de Educação Fundamental. 2 ed. Rio de Janeiro: PD\&A, 2000.

FERNANDES, Florestan. O desafio educacional. São Paulo. Editora Cortez (autores associados), 1989.

QUADROS, Ronice Müller de. O tradutor e intérprete de língua brasileira de sinais e língua portuguesa. SEESP, 2004.

SOUZA, Marcos Torres de; PORROZZI, Renato. Ensino de libras para os profissionais de saúde: uma necessidade premente. Revista Práxis, v. 1, n. 2, 2017.

KOSLOWSKI, Lorena. O modelo bilíngue/bicultural na educação do surdo. Anais do Seminário Surdez: Desafios para o próximo Milênio. Rio de Janeiro. INES, 2000.

MOREIRA, Antonio Flávio Barbosa e SILVA, Tomaz Tadeu da. (orgs.). CURRÌCULO, CULTURA E SOCIEDADE. $4^{\text {a }}$ Ed. São Paulo: Cortez, 2000.

SAVIANI, Demerval. Escola e Democracia. 34. ed. rev. Campinas, Autores Associados, 2001. (Col. Polêmicas do Nosso Tempo; vol. 5). 94 p.

SILVA, Tomaz Tadeu da. Documentos de Identidade: uma introdução às teorias do currículo. $2^{\mathrm{a}}$ Ed. Belo Horizonte: Autentica 2004.

SILVA, Tomaz Tadeu da. Documentos de Identidade: Uma Introdução às Teorias de Currículo . $3^{\circ}$ Edição. Editora Autêntica. 2010

SILVA, Vilmar et al. Educação de Surdos: uma releitura da primeira escola pública para surdos em Paris e do Congresso de Milão em 1880. Quadros RM, organizador. Estudos Surdos I. Petrópolis, Rio de Janeiro: Arara Azul, p. 14-37, 2006.

STAINBACK, S. et al. A aprendizagem nas escolas inclusivas: e o currículo?. In: STAINBACK, S. \& STAINBACK, W. Inclusão: Um guia para educadores. Tradução de Magda França Lopes. Porto Alegre: Artmed Editora S.A., p. 240 - 250. 1999.

[1] Professora/Interprete de libras, Pós graduada em Libras; Administração e Coordenação Escolar; cursando Mestrado em Educação na UDE - Universidade de la Empresa - Montevideo, ultimo período.

\section{PUBLIQUE SEU ARTIGO CIENTÍFICO EM:}

https://www.nucleodoconhecimento.com.br/enviar-artigo-cientifico-para-submissao 